\title{
FABRIC DESIGN PATTERN FEEDING THROUGH HUMAN MACHINE INTERFACE (HMI) FOR AN ELECTRONIC JACQUARD MECHANISM ON A SEMI-AUTOMATED CONVENTIONAL WEAVING LOOM
}

\author{
S.Rathinavel ${ }^{1}$ \\ ${ }^{1}$ Assistant Professor, Department of Electronics, PSG College of Arts \& Science, Tamilnadu, India
}

\begin{abstract}
This work mainly focused on improving performance of a semi-automated weaving loom by replacing conventional cylinder with solenoid array. A human machine interface (HMI) based system is introduced to ensure design edit on loom without the help of personal computer (PC). Solenoid arrays are controlled by a HMI and a simple microcontroller instead of PC. The technology behinds the viewable and editable designs of human machine interface without personal computer are explained. Design patterns are stored in either SD card or USB memory device in the format of bitmap. All hardware models are simulated and verified forsemi-automated conventional weaving loom.
\end{abstract}

Key Words: HMI, Microcontroller, Card, Electronic Jacquard, Solenoid Array, Semi Automated Loom, Fabric Design.

$* * *$

\section{INTRODUCTION}

The conventional mechanical Jacquard has cylinder to feed design pattern on fabric from punch card. The mechanical operation of the cylinder leads to very high temperature in the cabinet of jacquard machine. The existing electronic jacquard has no option to edit the design pattern on running condition of the loom and no option to vary the data transfer except few predefined baud rate like 4800bps, 9600bps and so on. The weaving speed of a loom mainly depends on the capable speed of jacquard machine [1]. The temperature of the jacquard machine cabinet never exceeded $48^{\circ} \mathrm{C}$ [2]. The proposed system has Solenoid array instead of cylinder. As a result it will reduce cabinet temperature significantly. The solenoid array is an external electronic unit and driven by a HMI instead of PC. Solenoids are energized according to bitmap file which is designed by CAD software. HMI reads the information of each row of a bitmap file. This information sends to the solenoid array to lift the corresponding warp ends (threads). Finally, appropriate designs are created on fabric.

The price of an electronic jacquard mechanism is too high because of the technology and large numbers of solenoids are involved in the process of design selection [3]. The designs which are designed in CAD can be edited by human machine interface itself without any help of PC. HMIs are used to display the entire design with highlighting the current row of the design to be sent to jacquard mechanism.

The operating software of HMI is responsible to display a pattern design and also to edit the design. The operating software includes various function keys for forward and reverses over the design to enhance the features of proposed electronic system. The main objective of this work is therefore to improve the response time of a jacquard mechanism, in that mechanical cylinder is replaced by a solenoid array and design patterns are displayed by HMI. The functional block diagram is presented to visualize the entire system. The communication between the system components is then explained. The operation software of HMI is not the concern of this study. Communication of HMI with solenoid arrays is also presented. Data latch Modules (DLM) is played a major role in data feeding process. Finally, HMI is used to view the entire fabric design which would be going to weave on fabric and it is also used to edit the design.

\section{METHOD OF EXPERIMENT}

The system consist of

1. System bus

2. HMI

3. SD Card

4. Microcontroller

5. Solenoids and

6. Data Latch IC.

Fabric designs are displayed in HMI and current row of the design is highlighted for the convenient of weaver. It communicates with microcontroller which is inside the control unit. The controller uses four ports to latch the digital values in the Data Latch Modules. Among these four ports three for output port and rest one for input port. All the ports are eight bit wide.

There are three types of buses involved in the system like address bus, data bus and control bus. If the size of the address bus is increased, the addressing capability of the system will increase significantly. It can be explained using the following formula.

Addressing capacity of the system $=2^{\text {n }}$

Where $\mathrm{n}$ is the size of the address bus. 
For example, $\mathrm{n}=2$ then addressing capacity of the system is 4 locations. If $\mathrm{n}=16$ then addressing capacity of the system will be 65536 locations. Here, the size of the data bus is 8 bit, control buses are used only when interrupt occur.

Latch IC 74L373 is responsible to energize a set of eight solenoids in a solenoid array. For example, a pattern need 120 hooks to complete its design without any repeat, then the required number of latch IC will be $120 / 8=15$. Similar calculation will be carried out for any number of hooks. The operation of the entire system extremely depends on its software. Three type of software used to run the entire system, they are

[1]. CAD - Computer Aided Design software is used to design the pattern in the format of any one of the standard picture file like bmp, tiff and so on. In textile industry, TexGraphics, Textronics, CadVantage Win Jacquard, AutoTex are mainly used to design patterns [4].

[2]. HMI Screen Editor Software- It reads the standard picture file, displays on the screen and finally sends to design selection control unit.

[3]. icrocontroller Code -The software inside the microcontroller is responsible for receiving the serial data, finally parallelized data sending to solenoid matrix through low level Data Latch Modules to implement the design pattern on fabric, must receive feedback signals from a Latch Modules and monitor the entire process by evaluating feedback signals.

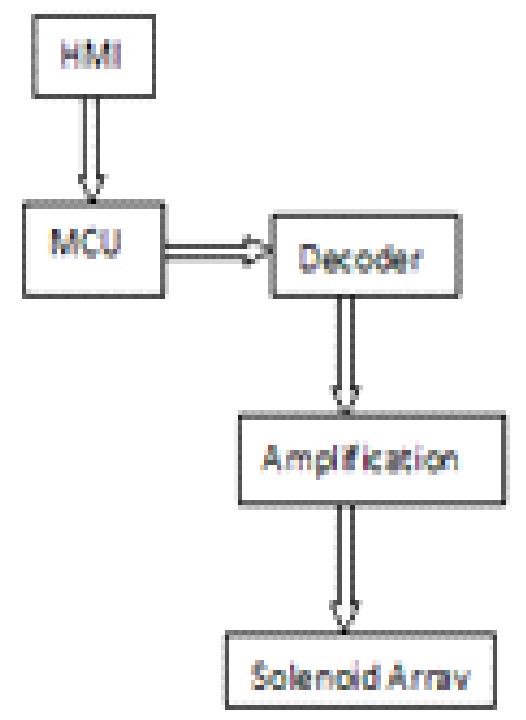

simplified block diagram proposed system.

Fig.1

\section{HMI MONITORING}

The picture file (bmp) stored SD card is inserted in to HMI, the operation software of HMI reads the picture file and displays on the screen. The number of pixels in a row of the picture is equal to number of hooks in a jacquard mechanism but there is no limitation for rows in a picture, it is because number of rows in a picture purely depends on size of the design. HMI is not only displayed the design pattern on the screen but also highlighted current row which would embossed on fabric. HMI sends the information of the image byte by byte to the microcontroller then microcontroller will latch by low level data latch modules.

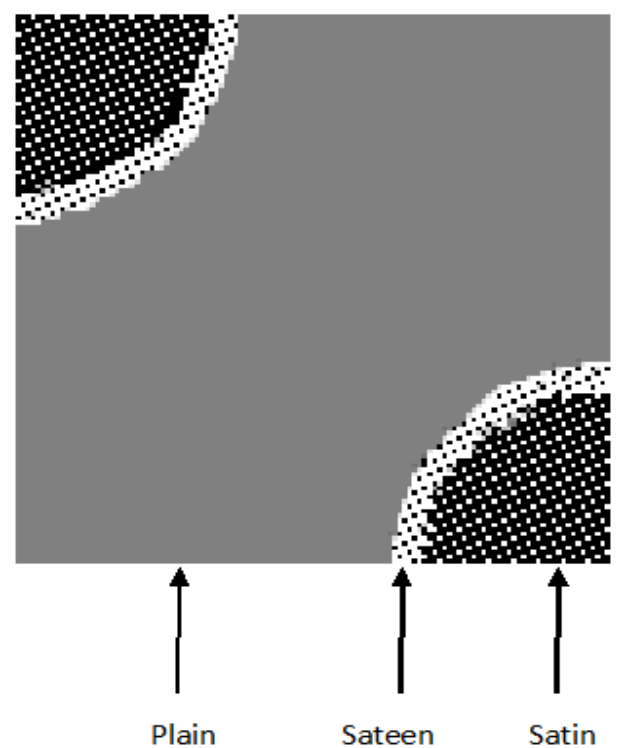

Fig.2. Sample pattern design.

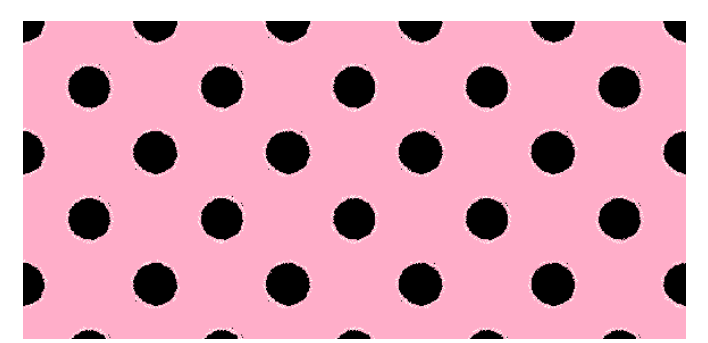

Fig.3. Actual design on fabric with multiple repeats of base design.

Three 8-bit digital output ports and one 8-bit digital input port are used to communicate with DLM. Two eight bit output ports of the microcontroller are used for address bus. Another eight bit output port is used for data bus. Once data are lied on data bus and its address on address bus, the values on data bus are latched by the corresponding DLM module to the address pointed by the instant value at the address bus.

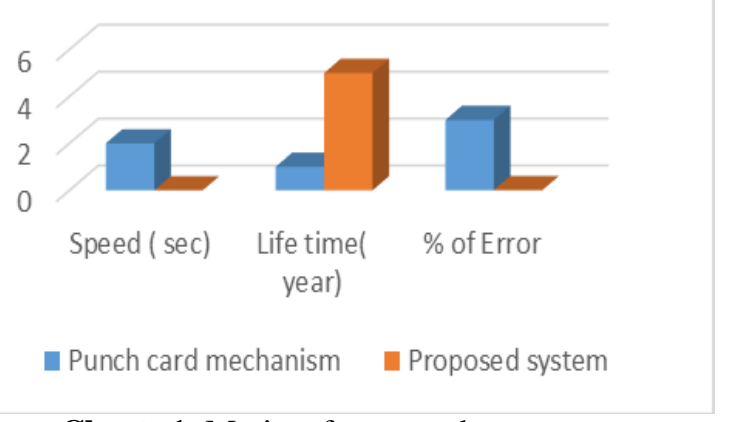

Chart -1: Merits of proposed system 


\section{DATA FEEDING}

Latch Module is the central part of electronic jacquard machine. Here the data feed to LM is sequence method instead of unique module address to identify the LMs. In the case of module address method there is a need to set jumper arrangement in the module and each address should compare with module address by a comparator.It is an unnecessary thing to feed data just $8 \times 8=64$ solenoids. This method is not suitable for which machines runs at higher RPM due to because 8-bit address comparator compares the address with module address which is set by jumpers. There is a problem in the unique module address method is jumper setting. It is not easy to setting the address for each module and it should be maintain forever. There will be a change to getting alter jumper setting by the weaver.

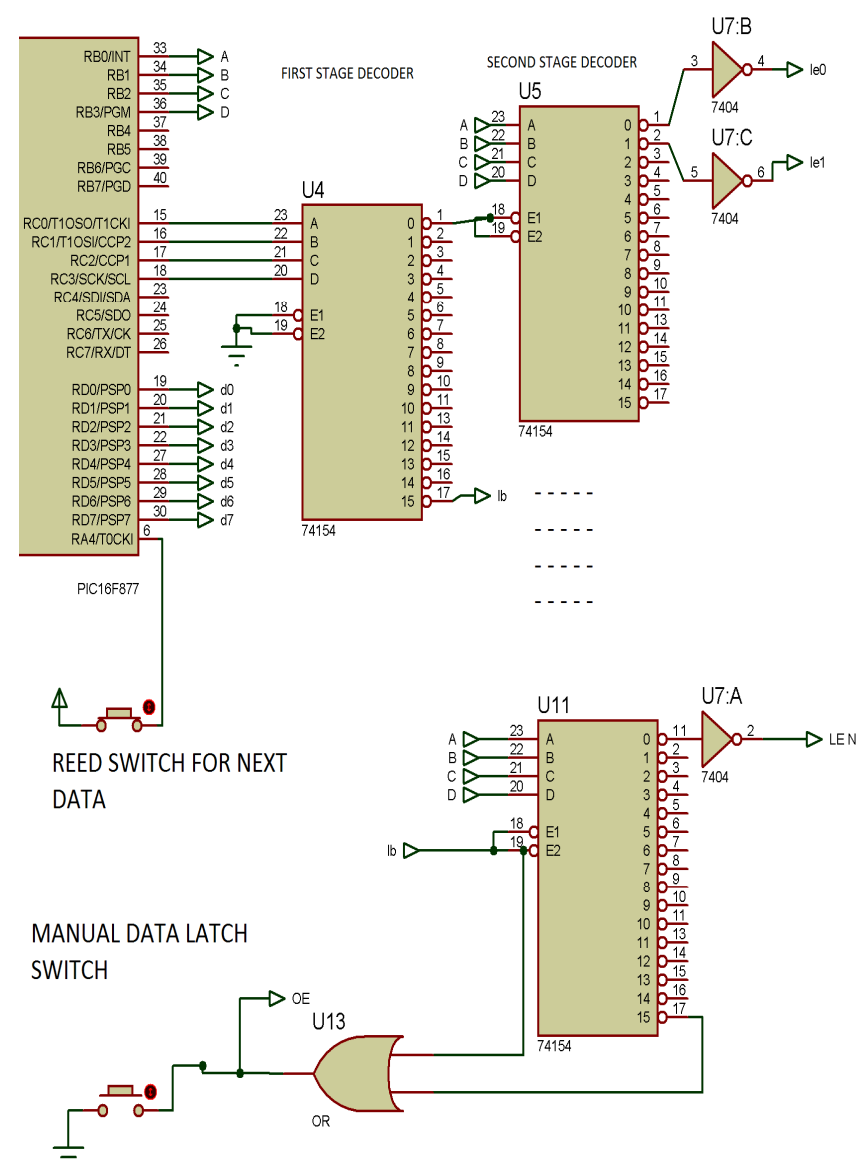

Fig 4. Data Latch Module.

Proposed system efficiently overcomes this problem, with two 4x16 decoder and 256 latch ICs. Each latch IC has eight bit. A $4 \times 16$ decoder connected with sixteen latch-ICs in order to control $16 \times 8=128$ solenoids. Totally sixteen $4 \times 16$ decoders are sits on the 4 bit(lower nibble of portB) bus which counts from $00 \mathrm{H}(00000000 \mathrm{~b})$ to $0 \mathrm{FH}(00001111 \mathrm{~b})$ higher nibble connection is no needed, these $4 \times 16$ decoders are enabled by a master $4 \times 16$ decoder which also counts from $00 \mathrm{H}(00000000 \mathrm{~b})$ to $0 \mathrm{FH}(00001111 \mathrm{~b})$. It is connected with portC, higher nibble connection is no needed. Each latch-IC sits on the data bus. Totally $16 \times 16 \times 8=2048$ solenoids are involved in this work, increasing the number of solenoids increases the resolution of the fabric design.
DATA LATCH

(256 NOs)

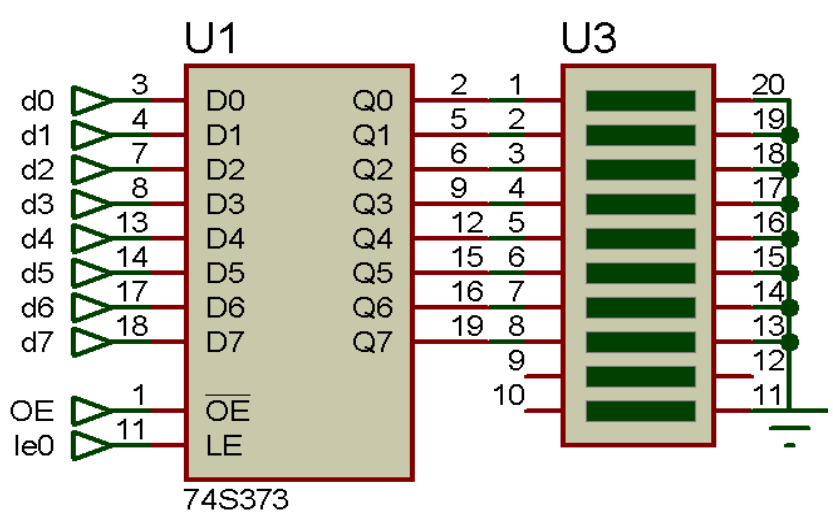

Fig. 5 Illustration shows Latch Module with solenoid array.

Table -1: Data feeding error

\begin{tabular}{|l|l|}
\hline OPERATING FREQUENCY & \% OF ERROR \\
\hline $10 \mathrm{KHz}$ & 0.003 \\
\hline $50 \mathrm{KHz}$ & 0.019 \\
\hline $1 \mathrm{MHz}$ & 0.043 \\
\hline $4 \mathrm{MHz}$ & 0.13 \\
\hline $8 \mathrm{MHz}$ & 0.72 \\
\hline $20 \mathrm{MHz}$ & 1.8 \\
\hline
\end{tabular}

\section{SOLENOID DRIVER}

The latch modules unable to drive the solenoids directly solenoids it is because the output of the latch module signal is TTL level. A Darlington pair is used to drive the solenoid directly. It is the name given to a pair of similar transistors so connected that emitter of one is directly joined to the base of the other. Darlington connection can be considered equivalent to two cascaded emitter followers.

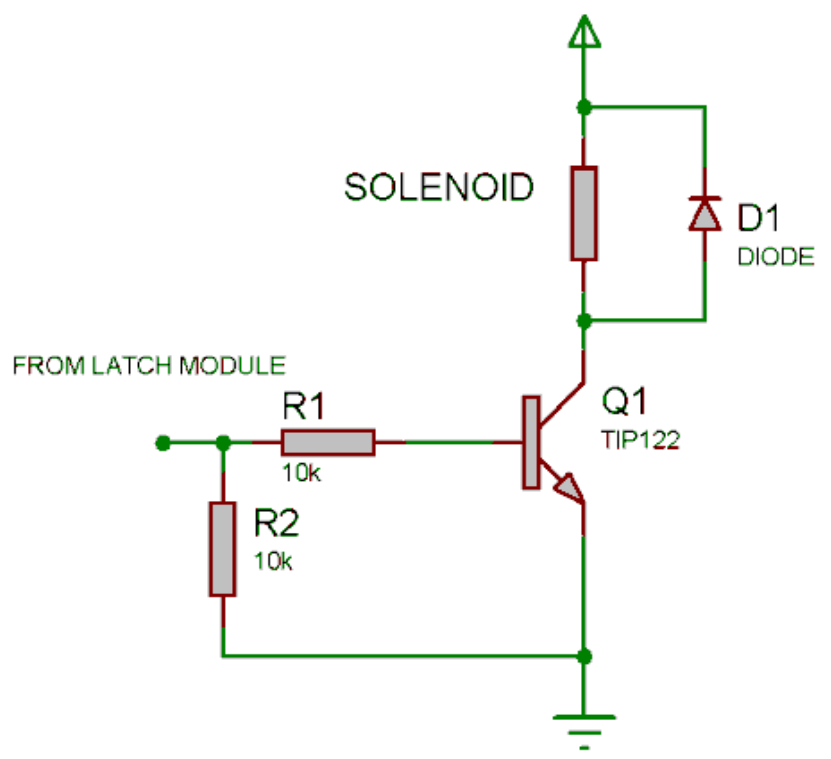

Fig 6. Solenoid Driver 
The current gain of a Darlington pair is

$\mathrm{A}_{\mathrm{i}}=\mathrm{I}_{\mathrm{E} .2} / \mathrm{I}_{\mathrm{B} .1} \beta_{1}, \beta_{2}=\beta^{2}$

For high current amplification, Darlington pair is required.

For instance, if the number of picks in a design is 240 , then the same numbers of punched cards are needed to implement the design on fabric. There are two process are involved in the preparation of punched cards. They are card making and card cutting processes, the manual card making process for 240 cards will take 64 minutes and also the manual card cutting process for 240 cards will take 110 minutes [5]. The proposed system having neither the card making process nor the card cutting process, it was taken only few 500 mille seconds to transfer the data from bmp image file to solenoid array.

\section{DISCUSSION \& CONCLUSION}

The total time saved by use of this work was calculated and compared with previous methods. The total percentage of time saved by use of the developed system varied from $90 \%$ to $230 \%$ based on number of hooks when compared with Electronic jacquard without HMI.

Time taken to edit fabric design

\begin{tabular}{|c|c|c|c|c|c|c|}
\hline Methods & $\begin{array}{l}\text { For } \\
120 \\
\text { hooks } \\
\text { /card } \\
\text { or } \\
\text { /row }\end{array}$ & $\begin{array}{l}\text { For } \\
240 \\
\text { hooks } \\
\text { /card } \\
\text { or } \\
\text { /row }\end{array}$ & $\begin{array}{l}\text { For } \\
400 \\
\text { hook } \\
\text { s } \\
\text { /card } \\
\text { or } \\
\text { /row }\end{array}$ & $\begin{array}{l}\text { For } \\
800 \\
\text { hook } \\
\text { s } \\
\text { /card } \\
\text { or } \\
\text { /row }\end{array}$ & $\begin{array}{l}\text { For } \\
1600 \\
\text { hook } \\
\text { s } \\
\text { /card } \\
\text { or } \\
\text { /row }\end{array}$ & $\begin{array}{l}\text { For } \\
2400 \\
\text { hook } \\
\mathrm{s} \\
\text { /card } \\
\text { or } \\
\text { /row }\end{array}$ \\
\hline $\begin{array}{l}\text { Manual } \\
\text { punch } \\
\text { method }\end{array}$ & $\begin{array}{l}2.9 \\
\text { hrs }\end{array}$ & $\begin{array}{l}3.3 \\
\text { hrs }\end{array}$ & $\begin{array}{l}4.1 \\
\text { hrs }\end{array}$ & $\begin{array}{l}4.8 \\
\text { hrs }\end{array}$ & $\begin{array}{l}5.3 \\
\text { hrs }\end{array}$ & $\begin{array}{l}5.6 \\
\text { hrs }\end{array}$ \\
\hline $\begin{array}{l}\text { Automati } \\
\text { c punch } \\
\text { method }\end{array}$ & $\begin{array}{l}57 \mathrm{mi} \\
\mathrm{n}\end{array}$ & $\begin{array}{l}1.2 \mathrm{hr} \\
\mathrm{s}\end{array}$ & $\begin{array}{l}1.3 \\
\text { hrs }\end{array}$ & $\begin{array}{l}1.5 \\
\text { hrs }\end{array}$ & $\begin{array}{l}1.7 \\
\text { hrs }\end{array}$ & $\begin{array}{l}2.1 \\
\text { hrs }\end{array}$ \\
\hline $\begin{array}{l}\text { Electronic } \\
\text { jacquard } \\
\text { without } \\
\text { HMI }\end{array}$ & $\begin{array}{l}20 \\
\min \end{array}$ & $\begin{array}{l}30 \\
\min \end{array}$ & $\begin{array}{l}37 \\
\min \end{array}$ & $\begin{array}{l}42 \\
\min \end{array}$ & $\begin{array}{l}49 \\
\text { min }\end{array}$ & $\begin{array}{l}53 \\
\min \end{array}$ \\
\hline $\begin{array}{l}\text { Electronic } \\
\text { jacquard } \\
\text { with HMI }\end{array}$ & $\begin{array}{l}6 \\
\min \end{array}$ & $\begin{array}{l}10 \\
\min \end{array}$ & $\begin{array}{l}13 \\
\min \end{array}$ & $\begin{array}{l}17 \\
\min \end{array}$ & $\begin{array}{l}22 \\
\min \end{array}$ & $\begin{array}{l}28 \\
\min \end{array}$ \\
\hline
\end{tabular}

The proposed system improved the performance of a semiautomated weaving loom by replacing mechanical cylinder with solenoids in a jacquard mechanism. It reduced time to implement a new pattern on fabric and reduced machine temperature significantly. The cabinet temperature never exceeded $42^{\circ} \mathrm{C}$ on full day running condition. The proposed system replaces the pc by a HMI and a simple microcontroller. HMI enhance the system by the means of display. The display helps to view the current design pattern on the fabric to be weaved and it can be edited by the user without PC and CAD software. It saves valuable time. Data feeding rate can be easily modified by microcontroller coding based on the stroke time of the loom. Also the speed of data feed can be changed by varying the RC value of the oscillator.

\section{REFERENCES}

[1]. Fox, T. "Mechanism of Weaving. Bombay", Universal Publishing Co (1993).

[2]. J. M. Jin, Y. Z. Yu, Z. X. Jin, B. C. Zhang, "Design and Implementation of Electronic Jacquard Cylinder", Applied Mechanics and Materials, Vols. 220-223, pp. 934-938, (Nov. 2012).

[3]. Dulger, M." Design of a PC Driven Selection Box for a Jacquard Mechanism on a Conventional Carpet Weaving Development, Vol.1,No.2,June 2009.

[4]. R G Panneerselvam, "Use of MS paint for jacquard graph designing and printing" Indian j fiber \&Tex Res 38(2013)186.

[5]. K. Shanmugasundram, M. Prakash "Study on impact of CAD/CAM tools on production of punched cards by Indian silk saree designer for Handloom industry”Procida CIRP 1 (2014) 818-823 ELSEVIER.

\section{BIOGRAPHIES}

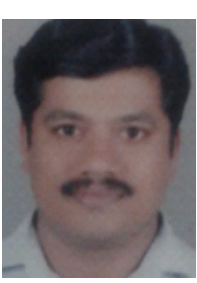

Mr.S.Rathinavel, currently working as an Assistant Professor in Electronics. $\mathrm{He}$ received MSc and MPhil in the year of 2006 and 2007 respectively. Also he has cleared UGC - NET in the year of 2013. His field of interest is Embedded System and Virtual Instrumentation. 